\title{
Febre maculosa brasileira em cães
}

\author{
Brazilian spotted fever in dogs
}

\section{Fernanda Silva Fortes ${ }^{1}$; Alexander Welker Biondo ${ }^{2}$; Marcelo Beltrão Molento ${ }^{3 *}$}

\section{Resumo}

A febre maculosa brasileira (FMB) é causada pela bactéria Rickettsia rickettsii, cuja patogenicidade é conhecida para seres humanos e cães, e o carrapato Amblyomma cajennense é tido como seu principal vetor. Os cães podem ter um papel significativo na epidemiologia da FMB devido ao próximo contato com seres humanos. Vários estudos sorológicos em cães em diferentes estados brasileiros indicaram um contato prévio destes animais com a $R$. rickettsii, sendo inclusive considerados sentinelas para a circulação da bactéria. Apesar de serem susceptíveis à infecção por $R$. rickettsii, a doença clínica em cães foi relatada apenas recentemente no Brasil, onde observaram-se sinais comuns da infecção, como febre, anorexia, letargia, anemia e trombocitopenia, os quais também podem ser encontrados em outras enfermidades, como a erliquiose monocítica canina, considerada a mais comum das doenças transmitidas por carrapatos em cães no país. Deste modo, o diagnóstico clínico de FMB em cães pode ser confundido com o de outras enfermidades, causando sua subnotificação. Além disso, a observação de sinais oculares em um cão infectado experimentalmente com cepa brasileira de $R$. rickettsii e sinais neurológicos em outro diagnosticado com FMB sugere que a doença seja semelhante à que ocorre nos Estados Unidos, onde tem sido predominantemente relatada. O objetivo do presente artigo de revisão sobre FMB em cães foi descrever aspectos epidemiológicos, clínicos e diagnósticos, incluindo ainda as principais medidas para seu tratamento e controle.

Palavras-chave: Febre maculosa brasileira, cães, carrapatos, Rickettsia rickettsii, Amblyomma sp.

\begin{abstract}
Brazilian spotted fever (BSF) is caused by bacteria Rickettsia rickettsii, highly pathogenic for humans and dogs, and has the Amblyomma cajennense tick as its main vector. Dogs maybe have a significantly participation on the BSF epidemiology, particularly in urban areas, due to the close contact with human beings. Several serologic studies in dogs from different Brazilian regions have indicated a previous contact of these animals with the $R$. rickettsii, and they are even considered as sentinels for the bacteria distribution. Although dogs are susceptible to $R$. rickettsii infection, the clinical disease in dogs has been very recently described in Brazil. Common signs of infection may include fever, depression, anorexia, ocular lesions, hemorrhagic petechiaes, anemia and thrombocytopenia, which also may appear in other diseases, such as the canine monocytic ehrlichiosis, considered the most common disease in dogs transmitted by ticks in Brazil. Thus, BSF clinical diagnosis in dogs may be confused by other diseases, causing its sub-notification. The aim of the present review article on BSF in dogs was to describe epidemiologic, clinical and diagnosis aspects, including also the main alternatives for its treatment and control.
\end{abstract}

Key words: Brazilian spotted fever, dogs, ticks, Rickettsia rickettsii, Amblyomma sp.

\footnotetext{
${ }^{1}$ Doutorando, Programa de Pós-Graduação em Ciências Veterinárias, Universidade Federal do Paraná, UFPR. Bolsista REUNI. E-mail: fortesfs@gmail.com

${ }^{2}$ Prof. Adjunto, Departamento de Medicina Veterinária, Universidade Federal do Paraná, UFPR. E-mail: abiondo@illinois.edu

${ }^{3}$ Prof. Adjunto, Departamento de Medicina Veterinária, Universidade Federal do Paraná, UFPR. Rua dos Funcionários, 1540, CEP 80035-050, Juvevê, Curitiba, PR. E-mail: molento@ufpr.br

* Autor para correspondência
} 


\section{Introdução}

A bactéria Rickettsia rickettsii, agente etiológico da febre maculosa brasileira (FMB), pode causar uma doença potencialmente fatal em seres humanos e cães (PADDOCK et al., 2002). Atualmente, é considerada uma zoonose reemergente no Brasil e de grande impacto para a saúde pública, devido à dificuldade de diagnóstico e à alta mortalidade em casos humanos não tratados precocemente (GRECA; LANGONI; SOUZA, 2008). A ocorrência da enfermidade em seres humanos já foi relatada desde a década de 20 em diferentes estados brasileiros, com maior prevalência encontrada em Minas Gerais (GALVÃO, 1988; LEMOS; MACHADO; COURA, 1994; CALIC, 1998) e São Paulo (MELLES; COLOMBO; SILVA, 1992; LEMOS et al., 1996; LEMOS et al., 2001). Em contrapartida, a doença clínica em cães foi descrita apenas recentemente no país, a partir da confirmação de FMB em dois animais procedentes do município de Itu, no estado de São Paulo (LABRUNA et al., 2009), destacando a gravidade da infecção e a dificuldade de diagnóstico na população canina. É importante citar que, no referido município, a enfermidade já fora relatada anteriormente em seres humanos, evidenciando a circulação do patógeno no local (LABRUNA et al., 2009).

A transmissão da FMB ocorre, principalmente, pela picada de carrapatos, sendo o Amblyomma cajennense considerado seu principal vetor (LABRUNA et al., 2004; GUEDES et al., 2005). Tanto em ambientes urbanos como em áreas rurais, os cães domésticos desempenham um papel epidemiológico particularmente importante, devido à aproximação de carrapatos infectados ao ambiente doméstico e no contato com o homem (PADDOCK et al., 2002). É provável que o convívio entre cães e seres humanos represente um risco para a infecção humana, devido ao estreito contato com os carrapatos (GORDON et al., 1984). Além disso, os cães são hospedeiros amplificadores desses artrópodes, aumentando o número de vetores infectados no ambiente (RAOULT; PAROLA, 2007).
Embora as informações sobre casos clínicos de FMB em cães ainda sejam escassas no Brasil, inquéritos sorológicos indicam que cães de áreas endêmicas, como São Paulo e Minas Gerais, estão expostos à infecção pela bactéria (SEXTON et al., 1993; LEMOS; MACHADO; COURA, 1994; LEMOS et al., 1996; HORTA et al., 2004; SANGIONI et al., 2005; LABRUNA et al., 2007a). Sabe-se, ainda, que o risco de contato com o patógeno é mais elevado em cães do que em seres humanos, tendo em vista a maior exposição dos animais a carrapatos vetores competentes (SCORPIO et al., 2008). Assim sendo, veterinários que atuam em áreas com notificação de FMB em seres humanos devem considerar a possibilidade de infecção canina e a solicitação de confirmação laboratorial para a obtenção de um diagnóstico preciso, além de auxiliar, dessa forma, a vigilância local da doença.

\section{Histórico}

A febre maculosa causada pela espécie $R$. rickettsii foi relatada pela primeira vez em seres humanos no ano de 1899, por Edward E. Maxey, na região montanhosa do noroeste dos Estados Unidos (EUA), onde a doença foi denominada febre maculosa das montanhas rochosas (FMMR) (HARDEN, 1990). No início do século XX, neste país, Howard T. Ricketts estabeleceu o papel do carrapato Dermacentor andersoni na transmissão da doença e realizou o primeiro isolamento da bactéria (RICKETTS, 1909), que foi nomeada Rickettsia em sua homenagem. No Brasil, assim como nos EUA, a febre maculosa foi descrita inicialmente em seres humanos, em 1929, conhecida então como tifo exantemático de São Paulo (TESP) (PIZA; MEYER; GOMES, 1932). Estudos realizados durante a década de 30 relacionando o "TESP e FMMR", concluíram que a doença verificada no Brasil era semelhante à norte americana. A doença passou a ser conhecida como febre maculosa brasileira (FMB) e sua transmissão associada a carrapatos Amblyomma cajennense (DIAS; MARTINS; RIBEIRO, 1937). 
Desde então, inúmeros casos humanos foram diagnosticados nos estados da região Sudeste e, somente no ano de 1978, houve a confirmação de $R$. rickettsii como agente causal (PHILIP et al., 1978).

A primeira inoculação de $R$. rickettsii em animais data de 1906, a partir de sangue de seres humanos infectados, cujo quadro clínico observado em cobaias de laboratório foi semelhante à FMMR humana (RICKETTS, 1906). Em 1933, foi demonstrada a susceptibilidade de cães à infecção pela bactéria (BADGER, 1933). Mais tarde, durante a década de 70 , foram observados sinais clínicos em cães após inoculação experimental com $R$. rickettsii, os quais foram similares aos analisados em seres humanos com FMMR (KEENAN et al., 1977a, 1977b). A primeira evidência de ocorrência natural da enfermidade em cães data de 1980 (LISSMAN; BENACH, 1980) e estudos subsequentes tem ampliado o conhecimento sobre a doença clínica em cães, assim como sua respectiva epidemiologia e patogenia (GREENE; BREITSCHWERDT, 2006).

Os casos clínicos de infecção por $R$. rickettsii em cães tem sido descritos predominantemente nos Estados Unidos, incluindo sinais como febre, letargia, anorexia, anemia e trombocitopenia (GRINDEM et al., 1999; GASSER; BIRKENHEUER; BREITSCHWERDT, 2001). Nesse país, foi demonstrado que a disfunção neurológica ocorre em até $43 \%$ dos cães acometidos, sendo a disfunção vestibulara anormalidadeneurológica possivelmente mais frequente (MIKSZEWSKI; VITE, 2005). Já, no Brasil, cães foram observados clinicamente após infecção experimental por $R$. rickettsii (PIRANDA et al., 2008) e, mais recentemente, houve o relato dos primeiros casos de infecção natural em cães provenientes do estado de São Paulo (LABRUNA et al., 2009).

\section{Etiologia}

A $R$. rickettsii é uma bactéria pertencente à família Rickettsiaceae e ordem Rickettsiales, pertencente ao grupo das bactérias Gram negativas, sendo pleomórfica e pequena $(0,3$ a $0,5 \mu \mathrm{m}$ por 0,8 a 2,0 $\mu \mathrm{m})$. É um organismo intracelular obrigatório, cujo principal alvo em animais vertebrados são as células endoteliais, nas quais o agente se multiplica, causando vasculites com a ativação de plaquetas e do sistema de coagulação (GREENE; BREITSCHWERDT, 2006). Já nos artrópodes vetores, a bactéria permanece em células intestinais, glândulas salivares e ovários (RAOULT; PAROLA; PADDOCK, 2005).

O gênero Rickettsia foi recentemente dividido em quatro grupos distintos: o grupo da febre maculosa (GFM), o grupo do tifo (GT), o grupo de transição (GTr) e o grupo ancestral (GA) (GILLESPIE et al., 2007). O GFM contém mais de 23 espécies válidas distribuídas em todos os continentes do mundo, exceto na Antártida, cuja transmissão está associada a carrapatos, sendo algumas capazes de causar doenças em animais vertebrados. A $R$. rickettsii é o principal agente etiológico do GFM e o de maior patogenicidade para seres humanos e cães, sendo que pode haver variação quanto à virulência dos genótipos circulantes da bactéria (PAROLA; LABRUNA; RAOULT, 2009). O GT contém as espécies Rickettsia prowazekii (agente causal do tifo epidêmico) e Rickettsia typhi (agente do tifo endêmico ou murino), transmitidas por piolhos e pulgas, respectivamente (EREMEEVA; DASCH; SILVERMAN, 2000). O GTr contém $R$. felis e $R$. akari, associadas a pulgas e a pequenos ácaros dos gêneros Ctenocephalides e Allodermanyssus, respectivamente. O GA é formado pelas espécies $R$. bellii e $R$. canadensis, ambas de patogenicidade desconhecida para animais (RAOULT; ROUX, 1997).

Em seres humanos, além da $R$. rickettsii, a patogenicidade de pelo menos 14 espécies do GFM já foi comprovada ( $R$. aeschlimannii, $R$. africae, $R$. akari, $R$. australis, $R$. conorii, R. felis, $R$. helvetica, $R$. honei, $R$. japonica, R. marmionii, $R$. mongolotimonae, $R$. parkeri, $R$. sibirica, $R$. slovaca) (RAOULT; ROUX, 1997; RAOULT et al., 2002). Em cães, a $R$. rickettsii é o agente mais 
importante responsável pelo desenvolvimento de quadros clínicos, observados em infecções naturais e experimentais (BADGER, 1933; KEENAN et al., 1977b; GASSER; BIRKENHEUER; BREITSCHWERDT, 2001). No entanto, com relação às demais espécies do GFM, ainda há poucas informações sobre seu efeito patogênico no cão, causando comumente infecções assintomáticas.

Após inoculação experimental com $R$. conorii em cães, não houve alterações clínicas ou laboratoriais nos animais, embora detectada soroconversão e riquetsemia por até 10 dias (KELLY et al., 1992). Entretanto, evidências sorológicas e moleculares associaram a manifestação de doença febril aguda em cães à infecção por $R$. conorii (SOLANO-GALLEGO et al., 2006). Cães inoculados experimentalmente com $R$. montana permaneceram saudáveis após observação clínica (BREITSCHWERDT et al., 1988). De forma similar, animais infectados com $R$. australis não apresentaram sinais clínicos nem riquetsemia, mesmo ocorrendo soroconversão (SEXTON et al., 1991).

\section{Vetores}

Os principais transmissores de Rickettsia spp. do GFM a animais vertebrados são os chamados "carrapatos duros" da família Ixodidae (RAOULT; PAROLA; PADDOCK, 2005). Nos EUA, os principais vetores de $R$. rickettsii são carrapatos do gênero Dermacentor e seu parasitismo é frequente em cães, os quais são responsáveis pela introdução de carrapatos ao ambiente humano (McDADE; NEWHOUSE, 1986). No Brasil, os principais vetores de $R$. rickettsii pertencem ao gênero Amblyomma, notadamente A. cajennense e A. aureolatum (PINTER; LABRUNA, 2006). Em geral, tal gênero caracteriza-se por ter uma baixa especificidade de hospedeiro, principalmente em suas fases imaturas, sendo o cão considerado hospedeiro primário de todos os seus estádios (LABRUNA et al., 2007b).
O carrapato Amblyomma cajennense, conhecido popularmente como "carrapato estrela" é o principal vetor de FMB, sendo encontrado em abundância nas regiões Sudeste e Centro-Oeste, com distribuição limitada nos demais locais (HORTA et al., 2004; SANGIONI et al., 2005). Apesar de cavalos, antas (Tapirus terrestris) e capivaras (Hydrochaeris hydrochaeris) serem os principais hospedeiros de A. cajennense, quando a população do ixodídeo está aumentada, ele pode se alimentar em uma ampla variedade de hospedeiros vertebrados. Entre estes, o cão doméstico merece destaque, sendo muitas vezes encontrado infestado por $A$. cajennense em diferentes áreas do Brasil (LABRUNA; PEREIRA, 2001).

O Amblyomma aureolatum, também chamado de "carrapato-amarelo-do-cão", é encontrado em áreas de Mata Atlântica das regiões Sul e Sudeste, onde as condições de alta umidade e temperaturas amenas predominam durante o ano todo (PINTER et al., 2004). O A. aureolatum já foi indicado como possível vetor de FMB na porção leste do estado de São Paulo (MORAES-FILHO et al., 2009), sendo considerado, em alguns locais endêmicos como o município de Mogi das Cruzes, o principal transmissor do agente a seres humanos (EVANS; MARTINS; GUGLIELMONE, 2000). Os canídeos, inclusive os cães domésticos, são os principais hospedeiros para carrapatos adultos de A. aureolatum e, em ambientes rurais próximos a remanescentes de floresta tropical, carrapatos adultos de A. aureolatum foram identificados parasitando principalmente a população de cães (EVANS; MARTINS; GUGLIELMONE, 2000). Nesses locais, os cães são expostos a carrapatos infectados com $R$. rickettsii, podendo adquirir a infecção e ainda representar um potencial risco para a transmissão humana ao carrearem os vetores para o ambiente domiciliar, possibilitando o contato do ixodídeo com seres humanos.

O Rhipicephalus sanguineus ("carrapato marrom do cão") é o principal carrapato que parasita cães no Brasil, principalmente em 
áreas urbanas (LABRUNA et al., 2004), sendo encontrado em todas as regiões brasileiras e capaz de sobreviver em ambientes fechados. Apesar de serem comumente encontrados em ambientes domésticos, raramente são relatados parasitando seres humanos (MORAES-FILHO et al., 2009). $R$. sanguineus é descrito no Brasil como um importante transmissor de patógenos como a Ehrlichia canis, Babesia vogeli, Hepatozoon canis e Mycoplasma haemocanis a cães. Além disso, há suspeitas de transmissão de Anaplasma platis, Borrelia burgdorferi, Babesia gibsoni, Rangelia vitalli e R. rickettsii (DANTAS-TORRES, 2008). Embora ainda não haja confirmação desse carrapato como vetor de FMB para cães e seres humanos no país, seu papel na transmissão do agente já foi confirmado nos EUA (NICHOLSON; GORDON; DEMMA, 2006) e no México (BUSTAMANTE; VARELA, 1947), além de haver suspeitas na Colômbia (LABRUNA et al., 2007a). Recentemente, a participação de $R$. sanguineus na epidemiologia de $R$. rickettsi no Brasil foi evidenciada pela primeira vez em uma área endêmica da região metropolitana de São Paulo (MORAES-FILHO et al., 2009). Ainda, foi relatada, pela primeira vez, a infecção natural por $R$. rickettsi em $R$. sanguineus em uma região rural do Rio de Janeiro com registros anteriores de casos humanos de FMB (CUNHA et al., 2009). Ambos os estudos mostram a possível participação dessa espécie de carrapato na transmissão da bactéria a seres humanos no Brasil.

\section{Transmissão}

A transmissão de Rickettsia spp. do GFM a animais vertebrados está comumente associada a carrapatos. Os cães são infectados com a $R$. rickettsii geralmente por meio da saliva de carrapatos infectados, durante sua picada no momento do repasto sanguíneo. Quatro a seis horas após a fixação do carrapato no hospedeiro há reativação da bactéria para o estado virulento, sendo regurgitada pelo artrópode, infectando o organismo no local de fixação (COMER, 1991).
Carrapatos infectados contêm uma grande quantidade de riquétsias do GFM em sua hemolinfa e fezes, e a transmissão do agente também pode ocorrer pelo contato do cão com tecidos ou fluidos do vetor infectado, se retirado de seu sítio de fixação erroneamente. No momento da remoção do artrópode, a pressão excessiva sobre o carrapato pode causar sua ruptura, expondo tanto o cão quanto o homem ao risco de contaminação (RAOULT; PAROLA, 2007). Em vários relatos de infecção por $R$. rickettsii em seres humanos, a remoção manual de carrapatos em cães foi o único fator de risco conhecido associado ao desenvolvimento da doença (SHEPARD; TOPPING, 1946; SEXTON; BURGDORFER, 1975).

\section{Reservatórios e Hospedeiros amplificadores}

Diversos gêneros de carrapatos, incluindo Dermacentor, Rhipicephalus e Amblyomma, são importantes reservatórios de $R$. rickettsii na natureza (BURGDORFER, 1988). Tais carrapatos desempenham esse papel devido à capacidade de transmitir a bactéria transovariamente (transmissão da bactéria entre sucessivas gerações) e transestadialmente (sobrevivência do agente em todos os estágios de vida). Assim, o carrapato permanece infectado durante toda a vida e é capaz de disseminar o organismo para as novas gerações. Entretanto, apenas esse mecanismo não é suficiente para manter a bactéria ativa ao longo do tempo, tendo em vista o efeito deletério que a mesma causa nos carrapatos (McDADE; NEWHOUSE, 1986).

Acredita-se que alguns animais vertebrados - hospedeiros naturais de carrapatos vetores potenciais - devam assumir um papel fundamental na manutenção do patógeno na natureza, atuando como hospedeiros amplificadores da infecção por $R$. rickettsii na população de carrapatos. Ao manter riquetsemia durante dias ou semanas, o hospedeiro amplificador possibilita a infecção de carrapatos antes não infectados e, assim, aumenta a infecção por $R$. rickettsii na população desses ixodídeos 
(BURGDORFER, 1988). Cinco características básicas devem ser consideradas em um animal vertebrado para que o mesmo seja considerado um hospedeiro amplificador da bactéria: ser abundante em área endêmica para febre maculosa; ser um bom hospedeiro natural do carrapato vetor; ser susceptível à infecção por $R$. rickettsii; manter níveis circulantes da bactéria na corrente sanguínea (riquetsemia) suficientes para causar infecção de carrapatos que nele se alimentem; e ter elevada taxa de renovação populacional, que significa a capacidade de entrada no meio ambiente de animais susceptíveis à doença (LABRUNA, 2006a).

$\mathrm{Na}$ América do Norte, o efeito amplificador de algumas espécies de pequenos roedores (Microtus pensilvanicus, Pitymus pinetorum, Peromyscus leucopus e Sigmodon hispidus) já foi determinado (McDADE; NEWHOUSE, 1986; BURGDORFER, 1988). Casos humanos de febre maculosa em foco endêmico no Arizona (EUA), associados à transmissão de $R$. rickettsii por $R$. sanguineus, levantaram a hipótese de os cães atuarem como hospedeiros amplificadores, pois todos os estádios do carrapato parasitam primeiramente o cão doméstico, que pode ter sido a fonte de infecção para os artrópodes (DEMMA et al., 2006).

No Brasil, diferentes trabalhos realizados desde a década de 30 apontam as capivaras (Hydrochoerus hydrochoerus) e os gambás (Didelphis spp) como amplificadores de $R$. rickettsii para $A$. cajennense (MOREIRA; MAGALHÃES, 1935; TRAVASSOS; VALLEJO, 1942a, 1942b; LABRUNA， 2006a; PIRANDA et al., 2008; HORTA et al., 2009). Além desses animais, também já foram indicados o cão doméstico (Canis familiaris); o cachorro do mato (Dusicyon sp., sin. Canis brasiliensis); o coelho do mato (Sylvilagus brasiliensis, sin. Sylvilagus minensis); o preá (Cavia aperea); e a cutia (Dasyprocta azarae) (MOREIRA; MAGALHÃES, 1935). Piranda et al. (2006) detectaram 20\% de carrapatos $R$. sanguineus infectados após alimentação em cães riquetsêmicos, sugerindo também um papel amplificador desse animal em áreas endêmicas para FMB.

\section{Hospedeiros sentinelas}

Cães que sobrevivem à infecção por Rickettsia rickettsii são capazes de produzir anticorpos (DEMMA et al., 2006) e, em todo o mundo, a sorologia em cães demonstrou ser um meio viável de determinar a exposição de seres humanos a Rickettsia spp. e predizer alterações na incidência de infecções em pessoas (RAOULT; PAROLA, 2007). Assim, os cães são considerados importantes sentinelas para riquetsioses, inclusive a FMB, em seres humanos. Tal fato se justifica, pois a soroprevalência para $R$. rickettsii em cães de determinadas áreas geográficas se aproxima da encontrada em seres humanos (BREITSCHWERDT et al., 1987). Além disso, existem relatos de casos de infecção em cães e seres humanos ocorrendo simultaneamente (PADDOCK et al., 2002; ELCHOS; GODDARD, 2003; ZAVALA-CASTRO et al., 2006).

Nos Estados Unidos, casos graves da infecção por $R$. rickettsii em seres humanos foram precedidos pela ocorrência da doença em cães, os quais foram associados à transmissão do agente para as pessoas (PADDOCK et al., 2002). No mesmo país, um caso humano fatal de FMMR ocorreu algumas semanas após a morte de dois cães deste paciente, provavelmente causado pela mesma doença (ELCHOS; GODDARD, 2003). Ambos os relatos enfatizam o papel do cão como sentinela para essa zoonose, sendo necessário haver maior comunicação entre veterinários e médicos quando se suspeita da incidência de zoonoses. A partir de inquéritos sorológicos para $R$. rickettsii em hospedeiros sentinelas, sobretudo o cão, pode-se determinar novas áreas para FMB e alertar proprietários de cães onde a bactéria é endêmica (PADDOCK et al., 2002; FREITAS, 2007).

Muitas infecções causadas por $R$. rickettsii são subclínicas, e um elevado percentual de cães aparentemente saudáveis que vivem em áreas endêmicas é soropositivo para a doença. No entanto, após o contato com o agente, a soropositividade persiste ao longo do tempo. A presença de animais 
sororeagentes indica a circulação de Rickettsia do GFM, em uma determinada área, pelo menos nos últimos 6-12 meses (PIRANDA et al., 2008). Deste modo, resultados sorológicos positivos não indicam necessariamente uma infecção recente. Entretanto, destaca-se a importância do cão como sentinela para a vigilância da FMB (PADDOCK et al., 2002; SANGIONI et al., 2005). Inquéritos sorológicos em cães provenientes de São Paulo, Minas Gerais, Espírito Santo, Rondônia e Paraná revelaram uma prevalência aparente de anticorpos anti-R. rickettsii que variou de 2 a 64\% (SEXTON et al., 1993; LEMOS; MACHADO; COURA, 1994; LEMOS et al., 1996; GALVÃO et al., 2002; HORTA et al., 2004; SANGIONI et al., 2005; FREITAS, 2007; LABRUNA et al., 2007a; PINTER et al., 2008; TAMEKUNI et al., 2008; TOLEDO et al., 2008; BATISTA et al., 2009). No entanto, é difícil estimar a real prevalência da infecção por $R$. rickettsii em cães por meio de provas sorológicos devido à possibilidade de reações cruzadas com outras espécies de Rickettsia do GFM (DANTASTORRES, 2008). Espécies não patogênicas, como $R$. bellii e $R$. rhipicephali, também podem estimular uma resposta imune em cães, protegendo esses animais contra infecções por $R$. rickettsii (RAOULT; PAROLA, 2007).

\section{Aspectos clínicos}

A infecção por $R$. rickettsii em cães vem sendo relatada principalmente nos Estados Unidos, sendo clinicamente semelhante à infecção causada em seres humanos (KEENAN et al., 1977b; BREITSCHWERDT et al., 1988; DAVIDSON et al., 1990). Foram relatadas taxas de letalidade em cães de 7\% (GREENE et al., 1985), 3\% (GREENE, 1987) e, mais recentemente, 0\% (GASSER; BIRKENHEUER; BREITSCHWERDT, 2001). Estudos experimentais em cães demonstraram que a gravidade da doença pode estar relacionada à dose infectante de $R$. rickettsii, levando a óbito animais inoculados com doses mais elevadas (KEENAN et al., 1977b). Além disso, cães recém chegados a áreas endêmicas ou que tiveram exposição primária a carrapatos sem a proteção materna de anticorpos podem apresentar um curso mais severo da infecção (LISSMAN; BENACH, 1980).

O período de incubação em cães pode variar de 2 a 14 dias após a transmissão da bactéria pelo carrapato. Os achados iniciais podem incluir febre $\left(39,2\right.$ a $\left.40,5^{\circ} \mathrm{C}\right)$, que surge 4 a 5 dias após a picada do carrapato, letargia, anorexia, depressão, epistaxe, petéquias e equimoses cutâneas, injeções esclerais e conjuntivite nas mucosas ocular, oral e genital. Sinais clínicos comuns também incluem tosse, dispnéia, aumento de sons broncovesiculares, linfadenite, perda de peso e desidratação dos animais (LISSMAN; BENACH, 1980; GREENE; BREITSCHWERDT, 2006). Edema de extremidades normalmente é encontrado envolvendo orelhas, lábios, mucosa peniana e escroto. Durante o estágio final da doença ou na convalescença, pode haver necrose de extremidades. Outros sinais podem ser observados nos cães como dor abdominal, diarréia, mialgia, poliartrite, além de envolvimento do sistema nervoso central (geralmente parestesia, ataxia e síndrome vestibular). Estudos têm demonstrado que ocorre disfunção neurológica em $43 \%$ dos cães acometidos, sendo a disfunção vestibular o sinal mais frequente (MIKSZEWSKI; VITE, 2005). Além dos danos neurológicos, as sequelas pósriquetsemia mais comumente encontradas em cães incluem lesões visuais e amputação de extremidades (BREITSCHWERDT et al., 1999). Alterações hematológicas incluem anemia, trombocitopenia, leucopenia leve após o aparecimento de febre, seguido por leucocitose (KEENAN et al., 1977a; GASSER; BIRKENHEUER; BREITSCHWERDT, 2001). Hipoalbuminemia, hipoproteinemia, hipocalcemia, hiponatremia e aumento de enzimas hepáticas são as alterações bioquímicas mais comumente associadas à infecção em cães (GREENE; BREITSCHWERDT, 2006).

No Brasil, a partir de infecção experimental em cães com o isolado brasileiro 'Taiaçu' de $R$. rickettsii, 
Piranda et al. (2008) verificaram a susceptibilidade dos animais à infecção pelo agente. Cães doentes apresentaram sinais clínicos semelhantes aos observados nos EUA, incluindo febre (acima de $39,5^{\circ} \mathrm{C}$ ), letargia e anorexia. Um cão apresentou lesões oculares, com congestão conjuntival e edema. O período de incubação variou de 3 a 13 dias. Quanto às alterações hematológicas, foi observada significativa diminuição na concentração de hemoglobina, no volume celular e na contagem de plaquetas durante o período febril. Não foi observada mudança acentuada nas contagens de eritrócitos e leucócitos. Nenhum cão apresentou hemorragia (cutânea ou de mucosas) e sinais neurológicos ou motores durante o experimento (PIRANDA et al., 2008). Tal estudo sugere que a gravidade da doença possa estar relacionada ao modo de aquisição da infecção, o qual consistiu na inoculação de doses elevadas de $R$. rickettsii nos animais e no parasitismo de carrapatos infectados. Mais recentemente, foram relatados os primeiros casos de FMB em dois cães naturalmente infectados provenientes do município de Itu, no estado de São Paulo, cujas manifestações clínicas foram similares às descritas por Piranda et al. (2008), exceto nos casos de anemia e lesões oculares (LABRUNA et al., 2009). Embora ainda existam poucos casos clínicos de FMB em cães no Brasil, veterinários que atuam em áreas com notificação de casos humanos devem considerar a possibilidade de ocorrência dessa doença e, quando necessário, solicitar exames laboratoriais a fim de obter um diagnóstico apropriado.

\section{Diagnóstico}

O diagnóstico da FMB em cães é baseado na observação de sinais clínicos e na confirmação laboratorial por meio de métodos diretos e/ou indiretos. É fundamental associar o diagnóstico laboratorial com a situação e os antecedentes epidemiológicos da região, a procedência do caso suspeito e a época do ano, para diferenciação de outras enfermidades. O histórico da exposição a carrapatos também é muito importante, por serem os principais transmissores da bactéria (GASSER; BIRKENHEUER; BREITSCHWERDT, 2001).

\section{Diagnóstico indireto}

O diagnóstico indireto é baseado em provas sorológicas, que são os métodos usuais. O diagnóstico de infecção por $R$. rickettsii em cães é realizado, geralmente, mediante a detecção de anticorpos séricos pela Reação de Imunofluorescência Indireta (RIFI). Em geral, só é possível detectar anticorpos anti-riquetsiais após a segunda semana do início da doença. Portanto, o diagnóstico definitivo poderá ser tardio em alguns casos (LA SCOLA; RAOULT, 1997). Para a confirmação diagnóstica, é necessário uma elevação de quatro vezes no título de anticorpos em amostras pareadas (GASSER; BIRKENHEUER; BREITSCHWERDT, 2001). Alternativamente, um título único maior que 1.024 também pode ser considerado indicativo de infecção (GASSER; BIRKENHEUER; BREITSCHWERDT, 2001). A RIFI é um teste simples e econômico com sensibilidade de 94 a 100\% e especificidade de $100 \%$, que detecta anticorpos $\operatorname{IgM}$ e $\operatorname{IgG}$ em amostras pareadas de soro, tanto na fase aguda da doença como na convalescença. Apesar de ser um teste altamente sensível, não distingue as espécies dentre os isolados, devido à possibilidade de reações cruzadas entre riquétsias do GFM (PAROLA; PADDOCK; RAOULT, 2005). Todavia, quando as amostras são testadas contra seu antígeno específico, o título resultante é mais elevado (PHILIP et al., 1978).

Quando uma amostra de soro é submetida a uma bateria de testes frente a variados antígenos de Rickettsia spp., as diferenças entre os títulos de anticorpos são, em alguns casos, grandes o suficiente para indicar a espécie de riquétsia que estimulou a resposta imune (PINTER et al., 2008). Ao apresentar um título final de anticorpos contra determinada espécie de Rickettsia pelo menos quatro vezes maior que o observado para quaisquer 
outras espécies, considera-se o soro homólogo à primeira espécie testada ou de genótipo muito estreitamente relacionado. Esse critério vem sendo utilizado em várias pesquisas sorológicas utilizando animais sentinelas no Brasil, para determinar o provável agente causador da infecção (HORTA et al., 2004; FREITAS et al., 2006; LABRUNA et al., 2007a; CUROTTO et al., 2008; PINTER et al., 2008; TAMEKUNI et al., 2008).

\section{Diagnóstico direto}

Alguns testes foram desenvolvidos para detectar diretamente as riquétsias a partir de materiais oriundos de pacientes em fase aguda da infecção e, assim, obter resultados positivos precocemente. Destacam-se a imunodetecção da bactéria em tecidos (imunohistoquímica) ou em células endoteliais extraídas de sangue total, o isolamento em cultura de células com o sistema "shell vial" e a amplificação de DNA riquetsial pela reação em cadeia da polimerase (PCR) (LA SCOLA; RAOULT, 1997).

Muito embora o isolamento da bactéria a partir de amostras de cães suspeitos seja possível, o procedimento pode levar algumas semanas (RAOULT; PAROLA, 2007). As amostras incluem plasma, triturado de coágulo, biópsia de pele, tecidos de necropsia e mesmo os artrópodes (LABRUNA, 2006b). O cultivo é feito principalmente de células Vero, associado ou não à técnica de "shell vial", com a penetração do agente no interior da célula. Com o isolamento por "shell vial", são obtidos resultados positivos durante a fase de riquetsemia, antes da soroconversão, sendo útil no diagnóstico de casos agudos (LA SCOLA; RAOULT, 1997).

As técnicas de biologia molecular usadas na detecção e identificação de riquétsias são baseadas na PCR, PCR associada à análise de polimorfismos de tamanho de fragmentos de restrição (PCR/ RFLP) e PCR-Sequenciamento. A PCR fornece resultados rápidos e é a prova de eleição para um diagnóstico precoce, fornecendo resultado antes da soroconversão e em pacientes previamente tratados. A espécie e o gênero do agente podem ser determinados por meio de sequenciamento e análise das bases dos produtos amplificados pela PCR. A PCR/RFLP apresenta resultados reprodutíveis, entretanto, o mesmo perfil eletroforético é observado em muitos isolados, dificultando a identificação das diferentes espécies do GFM (LA SCOLA; RAOULT, 1997).

É importante citar que a detecção de Rickettsia spp. em sangue de animais vertebrados normalmente é rara, uma vez que o período de bacteremia dura apenas alguns dias ou semanas e, posteriormente, a bactéria não é mais encontrada no sangue (BURGDORFER, 1988). O período de bacteremia da $R$. rickettsii já foi demonstrado em cães, com detecção do agente somente até 10 dias após infecção experimental (KIDD et al., 2008). Além disso, Rickettsia spp. infectam as células endoteliais dos animais, apresentando assim uma concentração muito baixa no sangue, dificultando a detecção por análise molecular (LA SCOLA; RAOULT, 1997).

\section{Diagnóstico diferencial}

O diagnóstico de FMB em cães é considerado um grande desafio, devido à inespecificidade dos sinais clínicos, além da possibilidade de ocorrer infecções subclínicas (DANTAS-TORRES, 2007; SCORPIO et al., 2008). A enfermidade pode ser confundida com outras doenças, devido à semelhança clínica entre elas, sendo necessário o diagnóstico diferencial contra erliquiose monocítica canina, doença de Lyme, babesiose, leishmaniose, hepatozoonose canina, doença de chagas, anaplasmose, hemobartonelose, e qualquer outra doença febril de origem inespecífica (DANTASTORRES, 2008). Além disso, a co-infecção de $R$. rickettsii com outros agentes transmitidos por carrapatos, tais como Ehrlichia canis, Babesia canis ou Bartonella vinsonii, deve ser considerada em cães com um quadro clínico grave ou atípico (KORDICK et al., 1999). 


\section{Tratamento}

O tratamento da FMB em cães é realizado com antibioticoterapia específica e seu sucesso está diretamente ligado ao achado da infecção no seu início. Quando a terapia é iniciada tardiamente, mesmo antibióticos eficazes podem não ser capazes de prevenir alterações patológicas, como necrose tissular ou danos neurológicos (GASSER; BIRKENHEUER; BREITSCHWERDT, 2001). Assim, a terapia antimicrobiana deve ser iniciada imediatamente após a suspeita clínica/ epidemiológica (RAOULT; PAROLA; PADDOCK, 2005). Nos EUA, cães com doença febril aguda oriundos de regiões endêmicas para FMMR, são rotineiramente tratados por médicos veterinários com terapia antimicrobiana dirigida contra $R$. rickettsii, mesmo sem a confirmação sorológica da infecção (BREITSCHWERDT et al., 1999).

Os fármacos de eleição para o tratamento da enfermidade nos cães são as tetraciclinas ( 25 a $30 \mathrm{mg}$ / $\mathrm{Kg}$ ), doxiciclina (10 a $20 \mathrm{mg} / \mathrm{Kg}$ ) ou cloranfenicol (15 a $30 \mathrm{mg} / \mathrm{Kg}$ ). A tetraciclina tem sido associada à grave nefrite em cães, além de ser contra-indicada para pacientes com azotemia grave ou progressiva. Drogas lipossolúveis, como doxiciclina, têm se mostrado mais efetivas, demonstrando ter menos reações adversas no tratamento da enfermidade e são consideradas de eleição para todos os pacientes suspeitos ou confirmados. Pesquisas a partir de cães com FMMR mostraram a eficácia dessa droga no tratamento da doença (BREITSCHWERDT et al., 1999). O tratamento precoce com doxiciclina (20 $\mathrm{mg} / \mathrm{Kg}$ via oral ou intravenosa a cada 12 horas por uma semana) melhora o prognóstico dos cães, com uma rápida resposta em um a dois dias (RAOULT; PAROLA, 2007).

Cloranfenicol também pode ser usado nos casos de hipersensibilidade a tetraciclinas; porém, seu uso é limitado devido a efeitos colaterais como a aplasia medular (RAOULT; PAROLA; PADDOCK, 2005; GREENE; BREITSCHWERDT, 2006; DANTASTORRES, 2007). Ainda, estudos experimentais em cães infectados indicaram que a fluoroquinolona enrofloxacina teve eficácia semelhante à tetraciclina e ao cloranfenicol para o tratamento da doença (BREITSCHWERDT et al., 1991). Entretanto, devido às injúrias causadas pela enrofloxacina em cartilagens, o uso deve ser evitado em cães jovens (GREENE; BREITSCWHERDT, 2006).

Devem-se instituir tratamentos de suporte como a fluidoterapia em cães desidratados, com falhas renais, choque ou diátese hemorrágica, a fim de minimizar a ocorrência de hipoperfusão em tecidos e órgãos com consequentes lesões renais, respiratórias e neurológicas (GREENE; BREITSCHWERDT, 2006).

\section{Prevenção e controle}

Atualmente, não há produção de vacinas comerciais contra FMB, e a prevenção da doença em cães depende do controle da população de carrapatos, tendo em vista que quanto maior a população desses artrópodes, maior o risco de infecção (RAOULT; PAROLA, 2007). O controle do vetor nos cães é realizado a partir da aplicação regular de acaricidas (DAVOUST et al., 2003). Os parasitas também podem ser retirados manualmente com auxílio de pinça e mortos preferencialmente em álcool ou água sanitária, ou pela aplicação de um inseticida, lavando as mãos cuidadosamente ao fim do processo (RAOULT; PAROLA, 2007). Além de se infectarem, os cães podem atuar como transportadores de carrapatos infectados. Assim, o controle desse artrópode no cão é um fator adicional importante para evitar a circulação de Rickettsia spp. no ambiente domiciliar humano.

O controle de carrapatos deve ser feito simultaneamente no ambiente a fim de impedir reinfestações nos cães ou o acometimento em seres humanos, pois as formas de vida livre do parasita são capazes de sobreviver por longos períodos sem hospedeiros. Medidas preventivas incluem a aplicação de acaricidas no meio e a manutenção da vegetação com corte baixo. Além disso, deve-se 
evitar a coexistência de diferentes espécies animais, sendo que a vedação adequada das casas pode impedir a entrada de animais silvestres em jardins e áreas recreativas para as quais possam trazer carrapatos (RAOULT; PAROLA, 2007).

Vale salientar que áreas sabidamente endêmicas devem contar com a colaboração da população para a prevenção e o controle da doença. Atividades educativas devem ser realizadas a fim de se esclarecer sobre os riscos para a saúde animal quando há contato entre animais de estimação e carrapatos infectados, além do risco zoonótico, de interesse em saúde pública. Em áreas de risco, como parques públicos, onde já se evidenciou a presença do vetor e ocorrência da doença, deve ser incentivada a vistoria do corpo a cada 2 a 3 horas, a utilização de roupas claras que facilitem a visualização do vetor, o uso de botas, além do esclarecimento sobre a forma correta de remoção do carrapato. Em tais áreas, deve ser evitado o acesso de cães e disponibilizada informação necessária por meio de avisos e placas em locais estratégicos (GRECA; LANGONI; SOUZA, 2008).

$\mathrm{O}$ treinamento de veterinários e médicos para o diagnóstico e tratamento precoce da FMB em cães e seres humanos, respectivamente, é um ponto relevante no controle e prevenção da doença, visando minimizar a sua ocorrência. Além disso, as pessoas que habitam locais de risco devem procurar as unidades básicas de saúde caso apresentem febre ou tenham sido picadas por carrapatos. Da mesma forma, cães que apresentem doença febril de origem inespecífica devem ser encaminhados ao veterinário.

\section{Conclusão}

Apesar de a ocorrência de FMB já ter sido descrita em seres humanos em vários estados brasileiros, o mesmo não ocorre com a população canina. No entanto, devido à maior exposição dos cães a carrapatos vetores potenciais e à susceptibilidade à infecção por $R$. rickettsii, é possível que ocorra maior incidência da doença em cães do que em seres humanos. A subnotificação da doença em cães pode ocorrer devido ao conhecimento limitado da epidemiologia da doença, aliado à ocorrência de sinais clínicos inespecíficos e à falta de inclusão no diagnóstico diferencial com outras doenças febris agudas por médicos veterinários. É necessário que os proprietários sejam informados sobre o risco de contato entre animais e vetores infectados. Assim, além de conduzir a um diagnóstico preciso da FMB em cães, os proprietários podem fornecer as informações necessárias para a vigilância da doença em cães e, consequentemente, em seres humanos. Em áreas onde há confirmação da FMB humana, médicos veterinários devem considerar a possibilidade de ocorrência da doença em cães e solicitar a confirmação laboratorial em casos suspeitos.

Pesquisas sorológicas em populações caninas são úteis para avaliar e monitorar a freqüência da FMB nas diferentes regiões do país, estabelecendo áreas de potencial risco para a transmissão da doença a cães e seres humanos, possibilitando a implantação de medidas profiláticas adequadas. Adicionalmente, o controle do carrapato vetor nos animais e no ambiente, aliado a ações de educação em saúde, são essenciais para a prevenção e o controle da doença.

\section{Referências}

BADGER, L. F. Rocky Mountain spotted fever: susceptibility of the dog and sheep to the virus. Public Health Reports, v. 48, n. 27, p. 791-795, 1933.

BATISTA, F. G.; SILVA, D. M.; GREEN, K. T.; TEZZA, L. B. L.; VASCONCELOS, S. P.; CARVALHO, G. S.; SILVEIRA, I.; MORAES-FILHO, J.; LABRUNA, M. B.; MOLENTO, M. B. Serological survey of spotted fever group Rickettsia sp. in horses and dogs in Almirante Tamandaré, Paraná, Brazil. In: WORLD ASSOCIATION FOR THE ADVANCEMENT OF VETERINARY PARASITOLOGY, 21., 2009, Calgary, Canadá. Anais... Calgary, 2009. CD-ROM.

BREITSCHWERDT, E. B.; DAVIDSON, M. G.; AUCOIN, D. P.; LEVY, M. G.; SZABADOS, N. S.; HEGARTY, B. C.; KUEHNE, A. L.; JAMES, R. L. Efficacy of chloramphenicol, enrofloxacin, and tetracycline for treatment of experimental Rocky 
Mountain spotted fever in dogs. Antimicrobial Agents and Chemotherapy, v. 35, n. 11, p. 2375-2381, 1991.

BREITSCHWERDT, E. B.; MONCOL, D. J.; CORBETT, W. T.; MacCORMACK, J. N.; BURGDORFER, W.; LEVY, M. G. Antibodies to spotted fever-group rickettsiae in dogs in North Carolina. American Journal of Veterinary Research, v. 48, n. 10, p. 1436-1440, 1987.

BREITSCHWERDT, E. B.; PAPICH, M. G.; HEGARTY, B. C.; GILBER, B.; HANCOCK, S. I.; DAVIDSON, M. G. Efficacy of doxycycline, azithromycin, or trovafloxacin for treatment of experimental Rocky Mountain spotted fever in dogs. Antimicrobial Agents and Chemotherapy, v. 43, n. 4, p. 813-821. 1999.

BREITSCHWERDT, E. B.; WALKER, D. H.; LEVY, M. G.; BURGDORFER, W.; COBERTT, W. T.; HURLBERT, S. A.; STEBBINS, M. E.; CURTINS, B. C.; ALLEN, D. A. Clinical, hematologic and humoral immune response in female dogs inoculated with Rickettsia rickettsii and Rickettsia montana. American Journal of Veterinary Research, v. 49, n. 1, p. 70-76, 1988.

BURGDORFER, W. Ecological and epidemiological considerations of Rocky Mountain spotted fever and scrubs typhus. In: WALKER, D. H. (Ed.). Biology of Rickettsial Diseases, Boca Raton, FL: CRC Press, 1988. p. 33-50.

BUSTAMANTE, M. E.; VARELA, G. Distribución de las rickettsiasis en Mexico. Revista del Instituto de Salubridad y Enfermedades Tropicales, v. 8, p. 3-14, 1947.

CALIC, S. B.; GALVÃO, M. A. M.; CHAMONE, C. B. Inquérito sorológico para febre maculosa em Belo Horizonte, Minas Gerais no ano de 1997. In: CONGRESSO DA SOCIEDADE BRASILEIRA DE MEDICINA TROPICAL, 34., 1998, Manaus. Anais... Manaus, 1998, p. 34.

COMER, M. K. Rocky mountain spotted fever. Veterinary Clinics of North America, v. 21, n. 1, p. 27-44, 1991.

CUNHA, N. C.; FONSECA, A. H.; REZENDE, J.; ROZENTAL, T.; FAVACHO, A. R. M.; BARREIRA, J. D.; MASSARD, C. L.; LEMOS, E. R. S. First identification of natural infection of Rickettsia rickettsii in the Rhipicephalus sanguineus tick, in the State of Rio de Janeiro. Pesquisa Veterinária Brasileira, v. 29, n. 2, p. 105-108, 2009.

CUROTTO, S. M. R.; FORTES, F. S.; SANTOS, L. C.; MORAES, W.; CUBAS, Z. S.; GRYCAJUK, M. C. H.; BARROS-FILHO, I. R.; PACHECO, R. C.; BIONDO, A. W.; MOLENTO, M. B.; LABRUNA, M. B. Rickettsia spp. serological diagnosis in capybaras (Hydrochaeris hydrochaeris) from Foz do Iguaçu, Brazil. In:
CONGRESSO, 11.; ENCONTRO ABRAVAS, 27., 2008, Santos. Anais... Santos: ABRAVAS, 2008. p. 76-79.

DANTAS-TORRES, F. Canine vector-borne diseases in Brazil. Parasites \& Vectors, v. 1, n. 1, p. 25, 2008.

Rocky Mountain spotted fever. The Lancet Infectious Diseases, v. 7, n. 11, p. 724-732, 2007.

DAVIDSON, M. G.; BREITSCHWERDT, E. B.; WALKER, D. H.; LEVY, M. G.; CARLSON, C. S.; HARDIE, E. M.; GRINDEM, C. A.; NASISSE, M. P. Vascular permeability and coagulation during Rickettsia rickettsii infection in dogs. American Journal of Veterinary Research, v. 51, n. 1, p. 165-170, 1990.

DAVOUST, B.; MARIÉ, J. L.; MERCIER, S.; BONI, M.; VANDEWEGHE, A.; PARZY, D.; BEUGNET, F. Assay of fipronil efficacy to prevent canine monocytic ehrlichiosis in endemic areas. Veterinary Parasitology, v. 112, n. 1, p. 91-100, 2003.

DEMMA, L. J.; EREMEEVA, M. E.; NICHOLSON, C. D.; TRAEGER, M. S.; BLAU, D. M.; PADDOCK, C. D.; LEVIN, M. L.; DASCH, G. A.; CHEEK, J. E.; SWERDLOW, D. L.; McQUISTON, J. H. An outbreak of Rocky Mountain Spotted Fever associated with a novel tick vector, Rhipicephalus sanguineus, in Arizona, 2004: preliminary report. Annals of the New York Academy of Sciences, v. 1078, p. 342-343, 2006.

DIAS, E.; MARTINS, A.; RIBEIRO, D. J. Thypho exanthematico no Oeste de Minas Gerais. Brasil Médico, v. 51, n. 24, p. 651-655, 1937.

ELCHOS, B. N.; GODDARD, J. Implications of presumptive fatal Rocky Mountain spotted fever in two dogs and their owner. Journal of the American Veterinary Medical Association, v. 223, n. 10, p. 1450-1452, 2003.

EREMEEVA, M. E.; DASCH, G. A.; SILVERMAN, D. J. Interaction of rickettsiae with eukaryotic cells: Adhesion, entry, intracellular growth, and host cell responses. Subcellular Biochemistry, v. 33, p. 479-516, 2000.

EVANS, D. E.; MARTINS, J. R.; GUGLIELMONE, A. A. A review of the ticks (Acari, Ixodida) of Brazil, their hosts and geographic distribution. 1. The State of Rio Grande do Sul, Southern Brazil. Memórias do Instituto Oswaldo Cruz, v. 95, n. 4, p. 453-470, 2000.

FREITAS, M. O. Detecção de Rickettsias do grupo febre maculosa em cães e eqüinos em São José dos Pinhais, PR. 2007. Dissertação. (Mestrado em Ciências Veterinárias) - Setor de Ciências Agrárias da Universidade Federal do Paraná, Curitiba.

FREITAS, M. O.; MOLENTO, M. B.; LABRUNA, M. B.; SILVEIRA, I.; BIONDO, A. W. Pesquisa de anticorpos específicos anti-rickettsia rickettsii em 
cavalos carroceiros em São José dos Pinhais, PR. In: CONGRESSO BRASILEIRO DE PARASITOLOGIA VETERINÁRIA, 14; SIMPÓSIO LATINOAMERICANO DE RICKETTSIOSES, 2., 2006, Ribeirão Preto. Anais... Ribeirão Preto: CBPV, 2006. p. 361.

GALVÃO, M. A. M. A Febre maculosa Brasileira em Minas Gerais e seus determinantes. 1988. Dissertação. (Mestrado) - Escola Nacional de Saúde Pública do Rio de Janeiro, Rio de Janeiro.

GALVÃO, M. A.; LAMOUNIER, J. A.; BONOMO, E.; TROPIA, M. S.; REZENDE, E. G.; CALIC, S. B.; CHAMONE, C. B.; MACHADO, M. C.; OTONI, M. E.; LEITE, R. C.; CARAM, C.; MAFRA, C. L.; WALKER, D. H. Rickettsioses emergentes e reemergentes numa região endêmica do Estado de Minas Gerais, Brazil. Cadernos de Saúde Pública, v. 18, n. 6, p. 1593-1597, 2002.

GASSER, A. M.; BIRKENHEUER, A. J.; BREITSCHWERDT, E. B. Canine Rocky Mountain spotted fever: a retrospective study of 30 cases. Journal of the American Animal Hospital Association, v. 37, n. 1, p. 41-48, 2001.

GILLESPIE, J. J.; BEIER, M. S.; RAHMAN, M. S.; AMMERMAN, N. C.; SHALLOM, J. M.; PURKAYASTHA, A.; SOBRAL, B. S.; AZAD, A. F. Plasmids and rickettsial evolution: insight from Rickettsia felis. PLoS One, v. 2, n. 3, p. 266, 2007.

GORDON, J. C.; GORDON, S. W.; PETERSON, E.; PHILIP, R. N. Epidemiology of Rocky Mountain spotted fever in Ohio, 1981: serologic evaluation of canines and rickettsial isolation from ticks associated with human case exposure sites. American Journal of Tropical Medicine and Hygiene, v. 33, p. 1026-1031, 1984.

GRECA, H.; LANGONI, H.; SOUZA, L. C. Brazilian spotted fever: a reemergent zoonosis. Journal of Venomous Animals and Toxins including Tropical Diseases, v. 14, n. 1, p. 3-18, 2008.

GREENE, C. E. Rocky mountain spotted fever. Journal of the American Veterinary Medical Association, v. 191, n. 6, p. 666-671, 1987.

GREENE, C. E.; BREITSCHWERDT, E. B. Rocky Mountain spotted fever, murine typhus-like disease, rickettsialpox, typhus, and Q Fever. In: GREENE, C. E. Infectious Diseases of the Dog and Cat. $3^{\text {rd }}$. ed., St Louis: Saunders Elsevier, 2006. p. 232-245.

GREENE, C. E.; BURGDORFER, W.; CAVAGNOLO, R.; PHILIP, R. N.; PEACOCK, M. G. Rocky Mountain spotted fever in dogs and its differentiation from canine ehrlichiosis. Journal of the American Veterinary Medical Association, v. 186, n. 5, p. 465-472, 1985.
GRINDEM, C. B.; BREITSCHWERDT, E. B.; PERKINS, P. C.; CULLINS, L. D.; THOMAS, T. J.; HEGARTY, B. C. Platelet-associated immunoglobulin (antiplatelet antibody) in canine Rocky Mountain spotted fever and ehrlichiosis. Journal of the American Animal Hospital Association, v. 35, p. 56-61, 1999.

GUEDES, E.; LEITE, R. C.; PRATA, M. C. A.; PACHECO, R. C.; WALKER, D. H.; LABRUNA, M. B. Detection of Rickettsia rickettsii in the tick Amblyomma cajennense in a new Brazilian spotted fever-endemic area in the state of Minas Gerais. Memórias do Instituto Oswaldo Cruz, v. 100, p. 841-845, 2005.

HARDEN, V. A. Rocky mountain spotted fever: history of a twentieth-century disease. Baltimore: Johns Hopkins University Press, 1990.

HORTA, M. C.; LABRUNA, M. B.; SANGIONI, L. A.; VIANNA, M. C. B.; GENNARI, S. M.; GALVÃO, M. A. M.; MAFRA, C. L.; VIDOTTO, O.; SCHUMAKER, T. T. S.; WALKER, D. H. Prevalence of antibodies to spotted fever group rickettsiae in humans and domestic animals in a Brazilian Spotted fever-endemic area in the state of São Paulo, Brazil: serologic evidence for infection by Rickettsia rickettsii and another spotted fever group Rickettsia. American Journal of Tropical Medicine and Hygiene, v. 71, n. 1, p. 93-97, 2004.

HORTA, M. C.; MORAES-FILHO, J.; CASAGRANDE, R. A.; SAITO, T. B.; ROSA, S. C.; OGRZEWALSKA, M.; MATUSHIMA, E. R.; LABRUNA, M. B. Experimental infection of opossums Didelphis aurita by Rickettsia rickettsii and evaluation of the transmission of the infection to ticks Amblyomma cajennense. Vector-Borne and Zoonotic Diseases, v. 9, n. 1, p. 109-118, 2009.

KEENAN, K. P.; BUHLES, W. C.; HUXSOLL JUNIOR, D. L.; WILLIAMS, R. G.; HILDEBRANDT, P. K. Studies on the pathogenesis of Rickettsia rickettsii in the dog: clinical and clinicopathologic changes of experimental infection. American Journal of Veterinary Research, v. 38, n. 6, p. 851-856, 1977a.

KEENAN, K. P.; BUHLES, W. C.; HUXSOLL JUNIOR, D. L.; WILLIAMS, R. G.; HILDEBRANDT, P. K.; CAMPBELL, J. M.; STEPHENSON, E. H. Pathogenesis of infection with Rickettsia rickettsii in the dog: a disease model for Rocky Mountain spotted fever. The Journal of Infectious Diseases, v. 135, n. 6, p. 911-917, 1977b.

KELLY, P. J.; MATTHEWMAN, L. A.; MASON, P. R.; COURTNEY, S.; KATSANDE, C.; RUKWAVA, J. Experimental infection of dogs with a Zimbabwean strain of Rickettsia conorii. American Journal of Tropical Medicine and Hygiene, v. 95, n. 5, p. 322-326, 1992. 
KIDD, L.; MAGGI, R.; DINIZ, P. P.; HEGARTY, B.; TUCKER, M.; BREITSCHWERDT, E. Evaluation of conventional and real-time PCR assays for detection and differentiation of spotted fever group Rickettsia in dog blood. Veterinary Microbiology, v. 129, n. 3/4, p. 294303, 2008.

KORDICK, S. K.; BREITSCHWERDT, E. B.; HEGARTY, B. C.; SOUTHWICK, K. L.; COLITZ, C. M.; HANCOCK, S. I.; BRADLEY, J. M.; RUMBOUGH, R.; MCPHERSON, J. T.; MacCORMACK, J. N. Coinfection with multiple tick-borne pathogens in a Walker Hound kennel in North Carolina. Journal of Clinical Microbiology, v. 37, n. 8, p. 2631-2638, 1999.

LABRUNA, M. B. Epidemiologia da febre maculosa no Brasil e nas Américas. In: SIMPÓSIO BRASILEIRO DE ACAROLOGIA, 1., 2006, Viçosa. Anais... Viçosa: UFV, 2006a. p. 63-78.

Cultivo celular de riquétsias no Brasil. In: CONGRESSO BRASILEIRO DE PARASITOLOGIA VETERINÁRIA, 14.; SIMPÓSIO LATINOAMERICANO DE RICKETTSIOSES, 2., 2006, Ribeirão Preto. Anais... Ribeirão Preto: CBPV, 2006b. p. 132-133.

LABRUNA, M. B.; HORTA, M. C.; AGUIAR, M. D.; CAVALCANTE, C. T.; PINTER, A.; GENNARI, M. S.; CAMARGO, L. M. Prevalence of Rickettsia infection in dogs from the urban and rural áreas of Monte Negro Municipality, Western Amazon, Brazil. Vector-Borne and Zoonotic Diseases, v. 7, n. 2, p. 249-256, 2007 a.

LABRUNA, M. B.; KAMAKURA, O.; MORAESFILHO, J.; HORTA, M. C.; PACHECO, R. C. Rocky Mountain spotted fever in dogs, Brazil. Emerging Infectious Diseases, v. 15, n. 3, p. 458-460, 2009.

LABRUNA, M. B.; PACHECO, R. C.; ATALIBA, A. C.; SZABO, M. P. J. Human parasitism by the capybara tick, Amblyomma dubitatum (Acari: Ixodidae). Entomological News, v. 118, n. 1, p. 77-80, 2007b.

LABRUNA, M. B.; PEREIRA, M. C. Carrapato em cães no Brasil. Clínica Veterinária, v. 6, n. 30, p. 24-32, 2001.

LABRUNA, M. B.; WHITWORTH, T.; HORTA, M. C.; BOUYER, D. H.; McBRIDE, J.; PINTER, A.; POPOV, V.; GENNARI, S. M.; WALKER, D. H. Rickettsia species infecting Amblyomma cooperi ticks from an area in the State of São Paulo, Brazil, where Brazilian spotted fever is endemic. Journal of Clinical Microbiology, v. 42, n. 1, p. 90-8, 2004.

LA SCOLA, B.; RAOULT, D. Laboratory diagnosis of rickettsioses: current approaches to diagnosis of old and new rickettsial diseases. Journal of Clinical Microbiology, v. 35, n. 11, p. 2715-2727, 1997.
LEMOS, E. R. S.; ALVARENGA, F. B. F.; CINTRA, M. L.; RAMOS, M. C.; PADDOCK, C. D.; FEREBEE, T. L.; ZAKI, S. R.; FERREIRA, F. C. C.; RAVAGNANI, R. C.; MACHADO, R. D.; GUIMARÃES, M. A. A. M.; COURA, J. R. Spotted fever in Brazil: A seroepidemiological study and description of clinical cases in na endemic área in the state of São Paulo. American Journal of Tropical Medicine and Hygiene, v. 65, p. 329-334, 2001.

LEMOS, E. R. S.; MACHADO, R. D.; COURA, J. R. Rocky Mountain spotted fever in an endemic área in Minas Gerais, Brazil. Memórias do Instituto Oswaldo Cruz, v. 89, n. 4, p. 497-501, 1994.

LEMOS, E. R. S.; MACHADO, R. D.; COURA, J. R.; GUIMARÃES, M. A. A.; CHAGAS, N. Epidemiological aspects of the Brazilian spotted fever: serological survey of dogs and horses in an endemic area in the state of São Paulo, Brazil. Revista do Instituto de Medicina Tropical de São Paulo, v. 38, n. 6, p. 427-430, 1996.

LISSMAN, B. A.; BENACH, J. L. Rocky Mountain spotted fever in dogs. Journal of the American Veterinary Medical Association, v. 176, n. 10, p. 994-995, 1980.

McDADE, J. E.; NEWHOUSE, V. F. Natural history of Rickettsia rickettsii. Annual Review of Microbiology, v. 40, p. 287-309, 1986.

MELlES, H. H. B.; COLOMBO, S.; SILVA, M. V. Febre maculosa: isolamento de Rickettsia em amostra de biópsia de pele. Revista do Instituto de Medicina Tropical de São Paulo, v. 34, p. 37-41, 1992.

MIKSZEWSKI, J. S.; VITE, C. H. Central nervous system dysfunction associated with Rocky Mountain spotted fever infection in five dogs. Journal of the American Veterinary Medical Association, v. 41, n. 4, p. 259-266, 2005.

MORAES-FILHO, J.; PINTER, A.; PACHECO, R. C.; GUTMANN, T. B.; BARBOSA, S. O.; GONZÁLES, M. A. R. M.; MURARO, M. A.; CECÍlIO, S. R. M.; LABRUNA, M. B. New epidemiological data on brazilian spotted fever in an endemic area of the State of São Paulo, Brazil. Vector-Borne and Zoonotic Diseases, v. 9, n. 1, p. 73-78, 2009.

MOREIRA, J. A.; MAGALHÃES, O. Thypho exantematico em Minas Gerais. Brasil Médico, v. 19, n. 21, p. 465-470, 1935.

NICHOLSON, W. L.; GORDON, R.; DEMMA, L. J. Spotted fever group rickettsial infection in dogs from eastern Arizona: how long has it been there? Annals of the New York Academy of Sciences, v. 1078, p. 519-522, 2006. 
PADDOCK, C. D.; BRENNER, O.; VAID, C.; BOYD, D. B.; BERG, J. M.; JOSEPH, R. J.; ZAKI, S. R.; CHILDS, J. E. Short report: concurrent Rocky Mountain spotted fever in a dog and its owner. American Journal of Tropical Medicine and Hygiene, v. 66, n. 2, p. 197-199, 2002.

PAROLA, P.; LABRUNA, M. B.; RAOULT, D. Tickborne rickettsioses in america: unanswered questions and emerging diseases. Current Infectious Disease Reports, v. 11, n. 1, p. 40-50, 2009.

PAROLA, P.; PADDOCK, C. D.; RAOULT, D. Tickborne rickettsioses around the world: emerging diseases challenging old concepts. Clinical Microbiology Reviews, v. 18, n. 4, p. 719-756, 2005.

PHILIP, R. N.; CASPER, E. A.; BURGDORFER, W.; GERLOFF, R. K.; HUGHES, L. E.; BELL, E. J.; Serologic typing of Rickettsiae of the spotted fever group by microimmunofluorescence. The Journal of Immunology, v. 121, n. 5, p. 1961-1968, 1978.

PINTER, A.; DIAS, R. A.; GENNARI, S. M.; LABRUNA, M. B. Study of the seasonal dynamics, life cycle, and host specificity of Amblyomma aureolatum (Acari: Ixodidae). Journal of Medical Entomology, v. 41, n. 3, p. 324-332, 2004.

PINTER, A.; HORTA, M. C.; PACHECO, R. C.; MORAES-FILHO, J.; LABRUNA, M. B. Serosurvey of Rickettsia spp. in dogs and humans from an endemic area for Brazilian spotted fever in the State of São Paulo, Brazil. Cadernos de Saúde Pública, v. 24, n. 2, p. $247-$ 252, 2008.

PINTER, A.; LABRUNA, M. B. Isolation of Rickettsia rickettsii and Rickettsia bellii in cell culture from the tick Amblyomma aureolatum in Brazil. Annals of the New York Academy of Sciences, v. 1078, p. 523-530, 2006.

PIRANDA, E. M.; FACCINI, J. L.; PINTER, A.; SAITO, T. B.; PACHECO, R. C.; HAGIWARA, M. K.; LABRUNA, M. B. Experimental infection of dogs with a Brazilian strain of Rickettsia rickettsii: clinical and laboratory findings. Memórias do Instituto Oswaldo Cruz, v. 107, n. 7, p. 696-701, 2008.

PIRANDA, E. M.; PINTER, A.; PACHECO, R. C.; FACCINI, J. L. H.; LABRUNA, M. B. Avaliação preliminar do cão doméstico como fonte de infecção por Rickettsia rickettsii para carrapatos Rhipicephalus sanguineus Laitreille, 1806 (Acari: Ixodidae). In: CONGRESSO BRASILEIRO DE PARASITOLOGIA VETERINÁRIA; 14., SIMPÓSIO LATINOAMERICANO DE RICKETTSIOSES, 2., 2006, Ribeirão Preto. Anais... Ribeirão Preto: CBPV, 2006. p. 366-366.
PIZA, J. T.; MEYER, J. R.; GOMES, L. S. Tipho exanthematico em São Paulo. Soc. Impress. Paulista, São Paulo, 1932.

RAOULT, D.; FOURNIER, P. E.; ABBOUD, P.; CARON, F. First documented human Rickettsia aeschlimannii infection. Emerging Infectious Diseases, v. 8, n. 7, p. 748-749, 2002.

RAOULT, D.; PAROLA, P. Rickettsial diseases. New York London: CRC Press, 2007.

RAOULT, D.; PAROLA, P.; PADDOCK, C. D. Tickbourne rickettsioses around the world: emerging diseases challenging old concepts. American Society for Microbiology, v. 18, n. 4, p. 719-756, 2005.

RAOULT, D.; ROUX, V. Rickettsioses as paradigms of news or emerging infectious diseases. Clinical Microbiology Reviews, v. 10, n. 4, p. 694-719, 1997.

RICKETTS, H. T. Some aspects of Rocky Mountain spotted fever as shown by recent investigations. Medical Record, v. 76, p. 843-855, 1909.

The study of "Rocky Mountain spotted fever" (tick fever?) by means of animal inoculations. A preliminary communication. Journal of the American Medical Association, v. 47, n. 1, p. 33-36, 1906.

SANGIONI, L. A.; HORTA, M. C.; VIANNA, M. C. B.; GENNARI, S. M.; SOARES, R. M.; GALVÃO, M.A. M.; SCHUMAKER, T. T. S.; FERREIRA, F.; VIDOTTO, O.; LABRUNA, M. B. Rickettsial infection in animals and Brazilian spotted fever endemicity. Emerging Infectious Diseases, v. 11, n. 2, p. 265-270, 2005.

SCORPIO, D. G.; WACHTMAN, L. M.; TUNIN, R. S.; BARAT, N. C.; GARYU, J. W.; DUMLER, J. S. Retrospective clinical and molecular analysis of conditioned laboratory dogs (Canis familiaris) with serologic reactions to Ehrlichia canis, Borrelia burgdorferi, and Rickettsia rickettsii. American Association for Laboratory Animal Science, v. 47, n. 5, p. 23-28, 2008.

SEXTON, D. J.; BANKS, J.; GRAVES, S.; HUGHES, K.; DWYER, B. Prevalence of antibodies to spotted fever group rickettsiae in dogs from southeastern Australia. American Journal of Tropical Medicine and Hygiene, v. 45, n. 2, p. 243-248, 1991.

SEXTON, D. J.; BURGDORFER, W. Clinical and epidemiologic features of Rocky Mountain spotted fever in Mississippi, 1933-1973. Southern Medical Journal, v. 68, n. 12, p. 1529-1535, 1975. 
SEXTON, D. J.; MUNIZ, M.; COREY, G. R.; BREITSCHWERDT, E. B.; HEGARDTY, B. C.; DUMLER, S.; WALKER, D. H.; PECANHA, P. M.; DIETZE, R. Brazilian spotted fever in Espirito Santo, Brazil: description of a focus of infection in a new endemic region. American Journal of Tropical Medicine and Hygiene, v. 49, n. 2, p. 222-226, 1993.

SHEPARD, C. C.; TOPPING, N. H. Rocky Mountain spotted fever: a study of complement fixation in the serum of certain dogs. The Journal of Infectious Diseases, v. 78, n. 1, p. 63-68, 1946.

SOLANO-GALLEGO, L.; KIDD, L.; TROTTA, M.; DI MARCO, M.; CALDIN, M.; FURLANELLO, T.; BREITSCHWERDT, E. Febrile illness associated with Rickettsia conorii infection in dogs from Sicily. Emerging Infectious Diseases, v. 12, n. 12, p. 1985-1988, 2006.

TAMEKUNI, K.; FILHO, M. F. S.; PACHECO, R. C.; LABRUNA, M. B.; VIDOTTO, O. Soroprevalência de Rickettsia spp. do grupo da febre maculosa em humanos, cães e eqüinos na região rural de Londrina-PR. In: CONGRESSO BRASILEIRO DE PARASITOLOGIA VETERINÁRIA, 15., 2008, Curitiba. Anais eletrônicos... CuTOLEDO, R. S.; TAMEKUNI, K.; FILHO, M. F. S.;
HAYDU, V. B.; PACHECO, R. C.; LABRUNA, M. B.; VIDOTTO, O. Infection by Rickettsia of the Spotted Fever Group in human, dogs, equine and Rickettsia spp. in ticks in Londrina, Paraná, Southern Brazil. In: INTERNATIONAL CONFERENCE ON TICKS AND TICK-BORNE PATHOGENS, 6., 2008, Buenos Aires. Anais... Buenos Aires. 2008. CD-ROM.

TRAVASSOS, J.; VALLEJO, A. Comportamento de alguns cavídeos (Cavia Aperea e Hydrochoerus capybara) às inoculações experimentais do vírus da febre maculosa. Possibilidade de esses cavídeos representarem o papel de depositários transitórios do vírus na natureza. Memórias Instituto Butantan, v. 15, p. 73-86, 1942a.

- Possibilidade de Amblyomma cajennense se infectar em Hydrochaeris capybara experimentalmente inoculada com vírus da febre maculosa. Memórias Instituto Butantan, Tomo XV, p. 87-90, $1942 \mathrm{~b}$.

ZAVALA-CASTRO, J. E.; ZAVALA-VELÁZQUEZ, J. E.; WALKER, D. H.; RUIZ ARCILA, E. E.; LAVIADAMOLINA, H.; OLANO, J. P.; RUIZ-SOSA, J. A.; SMALL, M. A.; DZUL-ROSADO, K. R. Fatal human infection with Rickettsia rickettsii, Yucatán, México. Emerging Infectious Diseases, v. 12, n. 4, p. 672-674, 2006. 